\title{
Functions of Nominalization in Scientific News Discourse
}

\author{
Li Qianbo ${ }^{1, \text { a }}$ \\ ${ }^{1}$ College of Foreign Language Education, China West Normal University \\ a2964660@qq.com
}

Keywords: nominalization; function; scientific news discourse

\begin{abstract}
Under the framework of systemic-functional linguistics, the present study makes much effort to demonstrate the specific functions of nominalization in scientific news discourse. Through the analysis of the data, the discovered functions of nominalization are conciseness, objectivity, formality, thematic connection, and pragmatic presupposition.
\end{abstract}

\section{Introduction}

Nominalization in English has attracted much attention. Nominalization is a kind of experiential grammatical metaphor. Nominalization refers to the fact that any element or group of elements shifts to function as noun or group in a clause, which includes nominalized adjectives, verbs, clauses(finite or non-finite) and so on (Halliday 2000: 351). Nominalization is the single most powerful resource for creating grammatical metaphor. By nominalization, “process (congruently worded as verbs) and qualities (congruently worded as adjectives) are reworded metaphorically as nouns instead of functioning in the clause as Process or Attribute, they function as Thing in the nominal group”. (Halliday 2000: 352)

\section{Nominalization Studies in Systemic-Functional Grammar}

Halliday(2000) for the first time puts forward the concept of grammatical metaphor in his book An Introduction to Grammatical Metaphor. And he also claims that nominalization is the single most important source of creating grammatical metaphor. Later, in his study, Halliday applies his grammatical metaphor theory into research of scientific and technology discourse, and draws the conclusion that the abundance of grammatical metaphor is one of the chief feature of English scientific and technology discourse. He also classifies grammatical metaphor in scientific and technology discourse into thirteen types and five of them are nominalization involving transferences from other functional elements to entity, all of which are basic element of processes in transitivity system. Theoretical motif is that nominalization strongly calls for a functional rather than purely structural approach. Halliday puts processes in a transitivity system and believes that nominalization is a process in which any element or group of elements is made to function as a nominal group in the clause. In functional grammar, "each element in language is explained by reference to its function in the total linguistic system” (Halliday, 1994:40), but not analyzed based on rules and principles. Attention is given to forms, meaning, relations and functions of nominal structures.

Moreover, the linguistic phenomenon of nominalization is treated in a clause, which constitutes the basic unit of discourse.

With the development of nominalization, more and more scholars, at home and abroad, study nominalization in the framework of grammatical metaphor.

Fowler(1991) in his book Language in the News points out that the correct use of nominalization can make us have a better understanding of the stylistic features peculiar to news discourse. Fowler(1991) carries out critical analysis of news discourse based on the theories of Halliday's systemic functional grammar. In his study, he focuses on the linguistic tools for the critical study, such as the analysis of transitivity in syntax, lexical structure and reported speeches. Fowler contributes a lot to the methodology of critical analysis of the news discourse. 


\section{The Studies of Scientific News Discourse}

In the 19th century, very few number of scientific news report can be found in public newspaper, and even these news often had no interests for ordinary people. However, the early part of 20th century saw great changes in the realm of science in western societies. Since 1970s, science news has made great progress both in quantity and in quality, resulting from the proliferation of scientific information and professional journalists. Since the last decade of the 20th century, scientific news has provided abundant information, which closely tracks the development of science in all categories. And the prevalence of internet services throughout the world speeds up the spreading of scientific news.

Beside numerous academic journals of science, almost all the famous news agencies and newspapers also devote themselves to the timely reporting of progress in science and technology. "Scientific news is the latest report on science and technology and natural phenomena. It may reflect human’s practices of recognizing and transforming nature.” (Sun Baoyin,1997)

In general, scientific news in print differs from those professional papers and popular science articles both in its aim and style. It primarily aims to report information about science and technology, rather than to introduce a profound theory or a new scientific discovery in exhaustive detail. But it does have close relation to the information of science and technology.

On the other hand, it may not totally distinguish itself from other forms of news reporting. Likewise, scientific news shares with them some common structural and linguistic features required by the style of news reporting (Wu Qianlong, 2001).

The particularity of scientific news, however, lie in its reporting objects. Science news reports usually deal with events which are correlative with the latest scientific developments and their social values. According to the specific topics involved in these events, scientific news may generally include reports on technical achievements, on scientists or other researchers, and on scientific policies. These special contents require scientific ne to conform to the scientific rules and the objective laws of nature. It should inform readers to be more normative than other form of news reporting, principally in the use of scientific terms. And last, the scientific news report itself must be succinct and less obscure, so as to interest ordinary people in keeping reading it.

\section{Specific Functions of Nominalization in Scientific News Discourse}

Scientific news has its specific stylistic requirements: the writing forms should be concise, the expression objective, the content concise and so on. This thesis thus concludes the specific functions of nominalization in scientific news discourse.

\section{Conciseness}

Halliday (1985:330) points out that "written language attains a high lexical density often accompanied by a relatively simple grammatical structure." Nominalization is the device in the grammar that allows scientific phenomenon to be described effectively by categorizing and labeling them.

Let's see the following examples:

In the retraction, published by Nature on Thursday, the researchers said, "Moreover, we have found inconsistencies between some of the features and data published in the paper and the original data. We have therefore lost confidence in the reported conclusions."

The geologists said the "new age for such a major valley confirms that on geological time scales the relief of the continents is continually remade by the interplay" of erosion and crustal uplift.

In example (1) and (2), we have 7nominalizaitons, through which the relationship of the processes is presented very clearly. If we use verbs or adjectives to express the same meaning, the structure may be terribly clumsy and broken, and we may find it difficult to determine the interrelations between the processes. Nominalization can transform a clause into a simple sentence so as to combine two phrases 
originating from two clauses into a simple sentence. It can also transfer the complicated predicate into an action noun with an article.

One more thing, packing information into a noun group allows us to utilize the full grammatical resources available to nouns such as having attributes (including post-attributes), being quantified, qualified, classified, etc. This device leaves the rest of the clause available for adding new information.

\section{Objectivity}

A noun typically refers to a "thing” and it is something that exists. "By 'nouning' a process into a thing, the writer can reflect the fact that he has negotiated and established the meaning of a clause centered around the process - in other words, that meaning now can be treated as existing, as a kind of abstract 'thing'." (Thompson, 1996:170)

Writers of scientific news are stating the phenomenon and process of objective things. They try to express the objective world in an objective way in written forms. To achieve this, "human being" is always replaced by the inanimate subject or nouns that indicate things to be the subjects. Also the "thing nouns" being the subject illustrate that the subject is not the agent of the actions by adjusting the process type. This transformation is accompanied with the nominalization. For example, the process of verbal transfers to process of relational, which delivers the content in a more objective way.

Moreover, Thompson (1996) points out nominalized processes are non-finite: they are not tied to any specific time in relation to the time of speaking, i.e. they are not indicative of time and modality. Both subject and finite which carries the modality and mood in a verbal process typically disappear when a process is nominalized. Thus, a nominalized process is detached from here-and-now in a way that is not normally possible for a process expressed by a verb. The nominals exist as a fact which does not allow the reader to negotiate.

\section{Formality}

Halliday points out that "Metaphorical modes of expression are characteristic of all adult discourses. The only examples of discourse without metaphor that we normally meet with are in young children's speech.”(Halliday, 1985:342) As a powerful realization form of grammatical metaphor, nominalization has a prominent stylistic function of formality in scientific news discourse, which has made nominalization become an indicator of written language. In scientific and technical registers, nominalization plays a role of developing the meaning step by step, using complex passages "packaged" in nominal form. In this way the text that is filled with nominalizations has formulated a kind of formality.

\section{Thematic Connection}

Nominalization contributes a lot to textual cohesion. Cohesion is created in some cases by relations between Theme and Rhema. According to Zhu and Yan(2001: 103), there are generally four types of patterns of thematic progression.

$$
\begin{aligned}
& \mathrm{T} 1-\mathrm{R} 1 \rightarrow \mathrm{T} 2(=\mathrm{T} 1)-\mathrm{R} 2 \\
& \mathrm{~T} 1-\mathrm{R} 1 \rightarrow \mathrm{T} 2-\mathrm{R} 2(=\mathrm{R} 1) \\
& \mathrm{T} 1-\mathrm{R} 1 \rightarrow \mathrm{T} 2(=\mathrm{R} 1)-\mathrm{R} 2 \\
& \mathrm{~T} 1-\mathrm{R} 1 \rightarrow \mathrm{T} 2-\mathrm{R} 2(=\mathrm{T} 1)
\end{aligned}
$$

Nominalization is especially helpful in realizing the simple linear progression: T1-R1 $\rightarrow$ $\mathrm{T} 2(=\mathrm{R} 1)-\mathrm{R} 2$, because the use of nominalization enables complex information in the previous clause to be packaged into a phrase which may function as Theme in the following clause. We therefore find the common pattern in formal discursive text where a meaning is brought in as a full clause, and is 
then encapsulated in a nominalization which serves as the starting-point for the next clause. For example:

(1) They(T1) slice and dice mangoes and other fruit that falls to the forest floor(R1). (2)Slicing off a piece(T2) is easily accomplished by a midsize ant with midsize mandibles (R2) and(3) having larger mandibles (T3) won't make a different in the size of the slice(R3).

In this passage, slicing and having are nominalizations. They package the Rhema of sentence(1) and(2) respectively and become the Theme of sentence(2) and(3). This is a kind of thematic connection which is called "linear progression" (McCarthy 1991). It can be demonstrated as the following pattern:

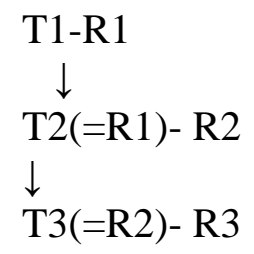

\section{Pragmatic Presupposition}

Pragmatic presuppositions are best described as a relation between a speaker and the appropriateness of a sentence in a context. Pragmatic presupposition highlights mutual knowledge between the speaker and the hearer. Presupposition generally relates to many words, phrases and structures, which are called presupposition triggers. Levinson (1983) lists 13 kinds of presupposition triggers. And in addition to these, Cheng Xiaotang(2003) argues that nominalization is also a way to realize presupposition. Nominalization realizes presupposition by converting a process to a thing and changing the thematic structure and the corresponding information distribution so that the unknown and unshared information formally becomes the known and share information. Thus, hidden message is smuggled in unnoticed. In news reporting, the presupposition realized by nominalization reflects the writer's ulterior motives. The presupposition fulfilled by nominalization often covertly shows media's attitude which in secret directs the mass to biased judgements.

\section{Conclusion}

As a language feature of scientific news discourse, nominalization has the rhetorical effects of condensation, thematic connection, formality etc. But unexpectedly, the thesis finds nominalizations also produce some conceived effects, say, superficial objectification and pragmatic presupposition that are secretly achieved by the purposefully used nominalized processes. But the discovery of this point is limited at

the present study, further and insightful study is necessary to guide readers to have a deeper understanding of news and the language in news.

\section{References}

[1] Fonteyn L, Smet H D, Heyvaert L. What It Means to Verbalize: The Changing Discourse Functions of the English Gerund[J]. Journal of English Linguistics, 2015, 43(1):36-60.

[2] Percy C. Andreas H. Jucker (ed.). Early Modern English News Discourse. Newspapers, Pamphlets and Scientific News Discourse[J]. Journal of Historical Pragmatics, 2011, 12(1-2):309-313.

[3] Bennett K. The Scientific Revolution and Its Repercussions on the Translation of Technical Discourse[J]. The Translator, 2011, 17(2):189-210. 
[4] Laslo E, Baram-Tsabari A, Lewenstein B V. A growth medium for the message: Online science journalism affordances for exploring public discourse of science and ethics[J]. Journalism: Theory, Practice \& Criticism, 2011, 12(7):847-870.

[5] Ahn M, Yap F H. Negotiating common ground in discourse: a diachronic and discourse analysis of maliya, in Korean[J]. Language Sciences, 2013, 37(3):36-51.

[6] Davies M. A New Approach to Oppositions in Discourse: The Role of Syntactic Frames in the Triggering of Noncanonical Oppositions[J]. Journal of English Linguistics, 2012, 40(1):41-73.

[7] Benitezcastro M A. Coming to Grips with Shell-nounhood: A Critical Review of Insights into the Meaning, Function and Form of Shell-noun Phrases[J]. Australian Journal of Linguistics, 2015, 35(2):168-194.

[8] Nielsen J A. Dialectical Features of Students' Argumentation: A Critical Review of Argumentation Studies in Science Education[J]. Research in Science Education, 2013, 43(1):1-23.

[9] Mairesse F, Walker M A. Controlling user perceptions of linguistic style: Trainable generation of personality traits[J]. Computational Linguistics, 2011, 37(3):455-488. 